\title{
CORPOREIDADE E EXISTÊNCIA: NOTAS DE UMA PERSPECTIVA FENOMENOLÓGICA SOBRE A CONDIÇÃO DA PESSOA COM DEFICIÊNCIA FÍSICA
}

\author{
Corporeity and Existence: Notes From a Phenomenological Perspective About the Condition of a \\ Physical Disability Person
}
Corporeidad y Existencia: Notas Desde una Perspectiva Fenomenológica sobre la Situación de las Personas con Discapacidad Física

\author{
ANDRÉa Luiza Da SiLVEIRA \\ Rita de Cássia Silveira CAmbruzzi \\ Maria da Piedade Resende da Costa \\ Rose Silveira Von Hertiwig
}

\begin{abstract}
Resumo: O presente artigo apresenta a corporeidade em uma perspectiva da fenomenologia de Sartre e Merleau-Ponty. Ambos consideram o corpo e o mundo como coextensivos e unificados na existência. De Merleau-Ponty adotamos o conceito de esquema corporal e hábito, fundamentados na percepção como consciência originária. E de Sartre empregamos os conceitos de corpo que Eu sou, corpo que Eu tenho e o corpo Para-outro, baseados no entendimento sobre a consciência como fluxo translúcido de mundo. Os conceitos de ambos expressam o corpo como psíquico. Os fenômenos humanos como motricidade, reflexão, representação e percepção são psíquicos. Segundo o preceito de voltar às coisas mesmas, a descrição parte da situação à ação e da ação à situação para compreender o significado do ato, tendo em vista que todo fenômeno humano se dá em ato. Ademais, a fenomenologia tem contribuído com a discussão sobre a corporeidade tanto no âmbito da educação quanto no campo da saúde apontando para a superação da dicotomia psíquico/corpo e a concepção do corpo máquina. Os referidos autores trazem à reflexão a deficiência física como uma forma de lançar-se no mundo, oferecendo os fundamentos para a intervenção psicológica no caso de uma pessoa com deficiência física, visto que o deficiente físico enfrentará algumas mudanças e possivelmente, necessita re-modelar seu esquema corporal levando em conta o corpo que Eu sou, o corpo que Eu tenho e o corpo Para-Outro.
\end{abstract}

Palavras-chave: Fenomenologia; Corporeidade; Deficiência física.

\begin{abstract}
The present paper presents the corporeity in a phenomenological perspective of Jean-Paul Sartre and Maurice MerleauPonty. Both authors consider the body and the world as co-extensive one to another and unified in the existence. From MerleauPonty is adopted the concept of corporeal schema and habit, based in perception as original consciousness. And from Sartre is applied the body concepts that I am, body that I have and the body For-other, based on the understanding about the consciousness as translucent flux of the world. The concepts of both of the phenomenologist express the body as psychic. The human phenomena as motor, insight, performance and perception are psychics. According to the precept of returning to the same things the description comes from the situation to action and from action to situation to understand the meaning of the act, since it is agreed that every human phenomenon is given in act. Moreover, the phenomenology has contributed with the discussion about the corporeity as in the education scope as in the health field pointing to the overcoming of a psychic/body dichotomy and the body machine conception. The referred authors bring to insight the physical disability as a way to launch into the world, offering the bases for the psychological intervention in the case of a person with physical disability. This fact is due to physically handicapped acquired that will face some changes and possibly needs to re-modulate the corporeal schema taking into account the body that I am, the body that I have and the body For-Other.
\end{abstract}

Keywords: Phenomenology; Corporeity; Physical disability.

Resumen: En este artículo se presenta la corporeidad de la perspectiva de la fenomenología de Jean-Paul Sartre y Maurice MerleauPonty. Ambos autores consideran el cuerpo y el mundo en la misma extensión entre sí y unidos en la existencia. Merleau-Ponty han adoptado el concepto de esquema corporal y el hábito, sobre la base de la percepción como consciencia original. Empleamos de Sartre los conceptos de cuerpo que soy, de cuerpo que tengo y el cuerpo a otro, basado en la comprensión de la conciencia como un flujo transparente en el mundo. Los conceptos de los fenomenólogos expresa todo el cuepo como psiquico. Los fenómenos humanos, como el movimiento, la reflexión, la representación y la percepción son psíquicos. De acuerdo con el precepto de devolver a las mismas cosas, la descripción parte de la situación a la acción y de la acción a la situación para comprender el significado del acto, dado que estamos de acuerdo en que todo fenómeno humano se produce en el acto. Por otra parte, la fenomenología ha contribuido a la discusión de la corporeidad, tanto en la educación y en salud que apunta a superar la dicotomía psíquico / cuerpo y el concepto de corpo como una máquina. Los autores aportan para reflejar la discapacidad física como una forma de poner en marcha en el mundo, proporcionando las bases para la intervención psicológica en el caso de una persona con discapacidad física. Esto se debe, teniendo en cuenta que la persona con discapacidad adquirida se enfrentan a algunos cambios y, posiblemente, tenga que volver a dar forma a su esquema corporal teniendo en cuenta el cuerpo que soy, el cuerpo que tengo y el cuerpo a otro. Palabras-clave: Corporeidad; Fenomenologia; Discapacidad fisica. 


\section{Introdução}

A noção de que o corpo está separado do psíquico extrapola os domínios da ciência e se estende à concepção do senso-comum. Expressões corriqueiras revelam o entendimento da separação do Ego em corpo e mente esta atividade é mental ou minha mente está cansada.

Para Ortega (2005a) no campo científico que costuma enredar o senso comum, cada vez mais a corporeidade é objeto de descrição e da explicação dos processos psíquicos. Há um corpo inerente a processos psíquicos. Pode-se conceber, junto com Sartre (1943/1997) e Merleau-Ponty (1945/2006) que todo o corpo é psíquico. Objetivamos neste artigo explorar o conceito de corporeidade a partir da perspectiva fenomenológica, sobretudo, no que se refere à corporeidade da pessoa com deficiência física.

Estudos realizados no âmbito da educação também têm nos auxiliado a refletir sobre a corporeidade integrada ao mundo vivido (Furlan, 1999; Gonçalves Junior, Ramos e Couto, 2003; Monteiro, 2009). A fenomenologia lançou as bases para tal compreensão e fundamenta esses estudos que renegam o conceito de corpo objeto e de corpo mecânico.

No que concerne à educação avança a idéia de que "as diferenças entre os corpos devem ser consideradas como possibilidades de troca de experiências e de aprendizagem, pois o fato deve residir na PD ser um corpo e não ter um corpo"1 (Rechineli, Porto \& Moreira, 2008, p. 306).

Reiterando este ponto de vista, Le Breton (2007) nos diz, a partir da sociologia do corpo, que a socialização da experiência corporal é uma condição social humana que em alguns períodos da existência, como na infância e na adolescência, é considerada um fator preponderante ao desenvolvimento humano.

O conhecimento sobre o desenvolvimento das crianças é fundamental para a educação não desprezando: a criança no seu contexto sócio-histórico a partir de sua história de vida e de sua família; o imaginário infantil como parte do processo de desenvolvimento; e, o conhecimento sobre a corporeidade como fundamental para uma aprendizagem adequada; a comunicação e a fala como estruturantes da relação com o outro; a necessidade de abrir-se a reflexão pedagógica para as “(...) experiências vividas das crianças e para as dinâmicas do conhecimento contemporâneo, da vida social e da cultura" (Nóbrega, 2007, p. 7).

No âmbito da saúde os estudos de Ortega (2005b, 2007) destacam a passagem do corpo real para o virtual, no qual "o virtual aparece como a ampliação do real e a materialidade do corpo-imagem nos é apresentada como a materialidade do corpo físico” (Ortega, 2007, p. 383)

PD - Pessoa deficiente, segundo o artigo original. discutindo os diagnósticos por imagens realizados pela medicina tomando a virtualidade pelo real. Mais uma vez nos deparamos com a ambiguidade entre o corpo como posse, ter um corpo, aquele corpo que aparece em imagem e o corpo que Eu-sou ser um corpo. A experiência fica em segundo plano enquanto ocorrer à primazia do virtual sobre o real, que na sociedade moderna nos atinge com veemência.

A análise realizada por Debord (2003) desdobrase para o que ele denomina "sociedade do espetáculo”. O referido autor entende que a primazia do virtual distorce a realidade da práxis social, do corpo, da história, do trabalho e do tempo fora do trabalho. A sociedade moderna encontra-se fragmentada enquanto destituída de seu poder prático e imbuída pelo império do espetáculo.

Ortega (2005a, p. 239), refere que: "A paixão pelo Real é, no fundo, uma paixão por um Real tornado virtual. Mas o virtual ou a hiper-realidade não é o Real, nem a imagem é a coisa, como o corpo não é redutível à sua imagem”. A consequência de tomar-se o corpo virtual em prejuízo do corpo real é que o corpo torna-se partes do corpo, isto é, a corporeidade perde sua carne. Esse aspecto ontológico vai implicar as questões éticas sobre, por exemplo, o transplante de órgãos e a posse dos genes que são considerados partes do corpo sem carne e sem existência, o que nos dá sinais da fragmentação das relações sociais e do próprio sujeito.

Segundo Debord (2003) a alienação que constitui tanto as relações sociais como as relações do sujeito consigo próprio pode ser observada na forma de apresentação do mundo como mercadoria abarcando tudo que é vivido. Pensamos que a fragmentação das relações sociais é correlativa a fragmentação do sujeito, portanto, da própria corporeidade. Para Ortega (2005b), o:

Desaparecimento social pode levar à disfunção biológica como no caso de distúrbios alimentares, anorexia e bulimia, ou vice-versa, quando a disfunção biológica pode levar ao desaparecimento social como acontece com muitos deficientes físicos. Vetores fenomenológicos e formas de desaparecimento social convivem com invariantes biológico-existenciais, tais como o caráter recessivo do interior do corpo (p. 1879).

Conseqüentemente, as diretrizes sócio-históricas e culturais, que esfacelam também a consciência do corpo, estão desvinculadas das condições reais de vida possibilitando a condição psicológica que leva, por exemplo, à anorexia e ao estigma referente à condição do deficiente físico. Todavia, a condição do deficiente físico é diversa dos transtornos biológico-existenciais. Há certa ambiguidade nas sociedades ocidentais no que se refere a conceitos cristalizados de normalidade e de deficiência. 
Erving Goffman expressa a contradição entre normalidade e deficiência quando diz:

Pedimos ao indivíduo estigmatizado negar o peso de seu fardo e de nunca fazer com que acredite que, ao carregá-lo, torna-se diferente de nós; ao mesmo tempo, exigimos que se mantenha a distância para que possamos manter a imagem que dele fazemos. Em outras palavras, sugerimos que aceite sua condição e que nos aceite, como forma de agradecimento pela tolerância natural que nunca realmente lhe concedemos. Assim, a aceitação imaginária está na origem da normalidade imaginária (Goffman, citado por Le Breton, 2007, p. 67).

Se por um lado há uma exigência que a pessoa com deficiência física seja tratada como uma "pessoa normal", por outro ela é excluída. Le Breton (2007) observa que tal exclusão ocorre, em grande parte, pelas dificuldades de locomoção por conta da infra-estrutura urbana que não está adaptada às suas necessidades.

Retratamos a dimensão sociológica da deficiência física como pano de fundo do vivido. Apontamos algumas nuances dessa dimensão, como o estigma da pessoa com deficiência física e a contradição entre uma exigência de normalidade e uma deficiência concreta de seu corpo afetando sua relação com o mundo. Além do desaparecimento social a que a pessoa com deficiência está fadada, quando lhe é negada as condições adequadas para sua participação na coletividade.

Marcamos a preeminência do irreal na sociedade do espetáculo, em que a imagem toma o lugar do concreto levando a uma alienação ainda mais profunda tendo como consequência a fragmentação do sujeito. Observamos, enfim, que a fenomenologia nos proporciona os fundamentos para esta compreensão por considerar a unificação corpo e mundo vivido na existência como pressuposto ontológico.

\section{Corpo, Existência e Mundo Vivido}

Corpo e mundo unificam-se na própria existência, logo, só há uma forma de existir, isto é: amar, sofrer, montar projetos, existindo corpo e consciência no mundo. Merleau-Ponty (1945/2006, p. 131) aponta que “a união entre alma e corpo não é selada por um decreto arbitrário entre dois termos exteriories, um objeto, outro sujeito. Ela se realiza a cada instante no movimento da existência”. Esta concepção de corpo coextensivo ao mundo, no decorrer da existência, é possível pelo fundamento ontológico da percepção, como consciência originária da relação com o mundo. Só se percebe, se vê, se locomove a partir de um corpo. De acordo com Le Breton (2007):
Pela corporeidade, o homem faz do mundo a extensão de sua experiência; transforma em tramas familiares e coerentes, disponíveis à ação e permeáveis à compreensão. Emissor ou receptor, o corpo produz sentidos continuamente e assim insere o homem, de forma ativa, no interior de dado espaço social e cultural (p. 8).

Desta forma, podemos assegurar com Sartre (1960/1987, 1943/1997) que todo fenômeno humano só se dá em ato, enche o mundo de sentido, é impregnado pelo sentido que está aí no mundo, é vivido, portanto, corporal. A descrição do fenômeno nos oferta o ato que se dá em situação. Sartre (1960/1987) utilizou-se do cinema mudo para exemplificar o sentido de tal ato em determinada situação. Como saber que naquela cena fazia frio? Pela ação dos personagens. A existência, nesse momento, equivale ao fazer-se na e pela realidade prática, pois o ato é uma negação do dado por um porvir. Seguindo o exemplo do filósofo francês, observava-se o frio pela maneira como os atores fechavam as janelas e a porta, assim, "No cinema mudo compreendia-se, pois a partir dos atos a significação objetiva das coisas" (Sartre, 1960/1987, p. 75).

Estes avanços da fenomenologia partem do panorama em que Husserl, de acordo com o que asseveram Dartigues (2000) e Merleau-Ponty (1945/2006), busca “voltar às coisas mesmas" e assinala uma psicologia descritiva desaprovando a ciência que vinha sendo produzida até então. Merleau-Ponty (1945/2006) postula que:

Tudo aquilo que sei do mundo, mesmo por ciência, eu o sei a partir de uma visão minha ou de uma experiência do mundo sem o qual os símbolos da ciência não poderiam dizer nada. Todo o universo da ciência é construído sobre o mundo vivido, e se queremos pensar a própria ciência com rigor, apreciar exatamente seu sentido e seu alcance, precisamos primeiramente despertar essa experiência do mundo da qual ela é a expressão segunda (p. 3).

O mundo está dado, está aí, anteriormente à descrição que pode ser feita dele, e somente a ação pode modificá-lo. Se quisermos conhecer a percepção, a representação ou a motricidade, será necessário descrevê-las engajadas no mundo, comprometidas no mundo, considerando-as tais e quais sucedem. A percepção como um modo de ser do corpo/consciência em nível pré-reflexivo, é o ato originário, por exemplo, a distinção da figura 'rosto da mãe' do fundo de mundo 'quarto do bebê'. A reflexão, que incide sobre o irrefletido é a condição de possibilidade para que a compreensão ocorra, desta forma:

[...] tomamos a situação objetiva e a partir desta situação objetiva que tentamos aprender vemos um homem 
que esclarece a situação agindo. Compreendemos seu ato pela situação, a situação pelo seu ato e, ambos, a um só tempo, acabam por nos fornecer uma compreensão acerca do que ele quer e do que sente (Sartre, 1960/1987, p. 73).

Para a fenomenologia de Sartre (1964/1968, 1960/1987) e Merleau-Ponty (1945/2006) a descrição contribui com os dados necessários à compreensão dos fenômenos humanos. E na descrição não poderemos descartar nada já que o mundo, o corpo e a existência são coextensivos um ao outro; levando-nos a verificar que não podemos explicar nem o físico pelo psíquico nem o psíquico pelo físico. O exemplo do braço fantasma, em que a pessoa sente o braço ausente, é utilizado por Merleau-Ponty (1945/2006, p. 122) para mostrar como "o corpo é o veículo do serno-mundo, e ter um corpo é, para um ser vivo, juntar-se a um meio definido, confundir-se com certos projetos e empenhar-se continuamente nele".

Assim, negar a deficiência é manter-se aberto às ações que somente o braço realiza, é guardar sua possibilidade de lançar-se ao que lhe é familiar como as tarefas corriqueiras. É na ação que a espacialidade do corpo se realiza encontrando como figura o objeto, que é a meta da ação no fundo de mundo, em cujo espaço físico contextualiza-se a ação, como, por exemplo, pegar a colher para tomar a sopa. Dentro desta perspectiva é que se pode afiançar o conceito de esquema corporal como "uma experiência de meu corpo no mundo, e que é ele que dá um sentido motor às ordens verbais" (Merleau-Ponty, 1945/2006, p. 196) ou a qualquer outro movimento.

Constituímos um esquema corporal na medida em que experimentamos um acordo entre o que está posto aí no mundo e aquilo que visamos pela ação. Assim, faz sentido dizer que temos um hábito ou hábitos que "está adquirido quando ele se deixou penetrar por uma significação nova, quando assimilou a si um novo núcleo significativo" (Merleau-Ponty, 1945/2006, p. 203). A relação com um instrumento de trabalho, seja um saxofone, um computardor ou uma tesoura ou um instrumento de locomoção como a cadeira de rodas, é esclarecida pelo que Merleau-Ponty (1945/2006) nos indica através do exemplo da relação do cego com sua bengala.

Quando a bengala se torna um instrumento familiar, o mundo dos objetos táteis recua e não mais começa na epiderme da mão, mas na extremidade da bengala. [...] As pressões na mão e a bengala não são mais dados, a bengala não é mais um objeto que o cego perceberia, mas um instrumento com o qual ele percebe. A bengala é um apêndice do corpo, uma extensão da síntese corporal. [...] A análise do hábito motor enquanto extensão da existência prolonga-se portanto em uma análise do hábito perceptivo en- quanto aquisição de um mundo. Reciprocamente, todo hábito perceptivo é ainda um hábito motor, e ainda aqui a apreensão de uma significação se faz pelo corpo. [...] ele é um conjunto de significações vivas que caminha para seu equilibrio (MerleauPonty, 1945/2006, p. 210).

Tanto a pessoa considerada normal quanto a pessoa com deficiência estão à mercê da impessoalidade da existência ao mesmo tempo em que a afetividade e o saber implicam a sua história pessoal. Uma grande decepção ou uma doença que modifica o corpo não determina a experiência. Além do fato, como por exemplo, de ser abandonado por quem se ama ou encontrar-se insatisfeito com seu peso, há a liberdade para fazer-se algo deste abandono ou desta insatisfação.

Permanecemos livres a respeito do sono e da doença na exata medida em que sempre permanecemos envolvidos no estado de vigília e de saúde, nossa liberdade apóia-se em nosso ser em situação, ela mesma é uma situação. Sono, despertar, saúde e doença não são modalidades da consciência ou da vontade, eles supõem um "passo existencial". A afonia não representa apenas uma recusa de falar, a anorexia uma recusa de viver, elas são essa recusa do outro ou essa recusa do futuro arrancadas da natureza transitiva dos "fenômenos interiores", generalizadas, consumadas, tornadas situação de fato (Merleau-Ponty, 1945/2006, p. 227).

Compreender as tramas da existência histórica e pessoal irá viabilizar o entendimento da situação da pessoa com deficiência. Certamente haverá generalidades da condição de deficiente como a do estigma ou o desaparecimento social. Entretanto, viver as dificuldades de locomoção como fracasso pessoal ou como desafio será a expressão da liberdade. O mundo está dado, ou seja, aquelas calçadas e rampas exatamente como são. Modificar alguns de seus aspectos envolve uma política pública. Atuar frente à realidade e de acordo com as possibilidades inscritas no mundo configura-se como a expressão da liberdade. Diferente ou deficiente? Ora, o corpo como um lançar-se no mundo, ambos unificados na existência, refere-se apenas a um corpo com sua condição específica. Um corpo deficiente se lança no mundo organizado para a pessoa considerada normal. É preciso antes adotar uma visão crítica sobre a organização do próprio mundo a fim de proporcionar à pessoa com deficiência, com sua corporeidade específica, as condições necessárias e urgentes de inserção nos espaços coletivos, de relação com os outros e de um futuro de realizações. Assim, demarcamos o corpo como uma "condição existencial primordial” (Schneider, 2002, p. 183) tanto quanto o mundo, a temporalidade e o outro. 


\section{O Contraponto do Corpo que Eu sou e o Corpo que Eu Tenho e o Corpo Para-Outro}

Existimos em nosso corpo, estamos sempre situados, desde o nascimento e ao longo de toda a existência em algum lugar em meio aos instrumentos e utensílios e como presença ou ausência para o outro. O corpo tal como aparece em imagem ou dissecado não poderia ser vivido. A experiência de existir só ocorre no meio do mundo, assim, Sartre afirma:

O homem e o mundo são seres relativos, e o princípio de ser é a relação. Segue-se que a relação primeira vai da realidade humana ao mundo. [...] Assim, o mundo devolve-me esta relação unívoca que é meu ser, pela qual faço com que este ser se revele. $O$ ponto de vista do conhecimento puro é contraditório: só existe o ponto de vista do conhecimento comprometido. Equivale dizer que conhecimento e ação não passam de duas faces abstratas de uma relação original e concreta (Sartre, 1943/1997, p. 390).

O corpo que Eu sou é vivido pré-reflexivamente e nos é indicado pelos seus arredores compostos pelos instrumentos-utensílios. O corpo que Eu sou está no meio do mundo como ação no mundo. "Assim, o mundo, como correlato das possibilidades que sou, aparece, desde meu surgimento, como o enorme esboço de todas as minhas ações possísveis" (Sartre, 1997, p. 407). O corpo que Eu sou é o corpo vivido.

O corpo que Eu tenho é o corpo retomado por uma consciência reflexiva. Aparece à reflexão como minha mão, meu pé, meu cérebro. "É o corpo tomado como abstrato, reflexivamente, fora de seu contexto, de sua vivência [...]" (Schneider, 2002, p. 183). É o corpo como posse.

O corpo-para-outro é o olhar do outro sobre nosso corpo. Na relação com o outro "Devo captar primeiramente o outro como aquele para quem existo como objeto [...]" (Sartre, 1943/1997, p. 427). Objetivados pelo outro é que experimentamos o corpo alienado, uma apreensão do outro sobre nosso corpo que não controlamos, que está sob o poder do outro. Sartre (19431997) explica que:

A experiência de minha alienação faz-se em e por estruturas afetivas, como a timedez. "Sentir-se enrubescer", "sentir-se transpirando" etc. são expressões impróprias que o tímido usa para explicar seu estado: o que ele quer dizer com isso é que tem consciência viva e constante de seu corpo tal como é, não para si mesmo, mas para o outro (p. 443).

Conhecemos nosso corpo a partir destas dimensões. Portanto, é importante levá-las em consideração na ten- tativa de compreender a corporeidade tanto de um coletivo como de pessoas idosas, pessoas com obesidade, pessoas com deficiência, entre outras, como o impacto da corporeidade irreal no uso do fotoshop, por exemplo. Corpos irreais, modificados por instrumentos da mídia servem de modelo pela busca da perfeição. Porquanto deve ocorrer a distorção entre o real e o virtual pautada pela "loucura" de se ter um corpo perfeito, implicando um congelamento do tempo histórico enquanto "ser-nahistória" que envelhece, que emagrece, que engorda entre outros.

\section{A Condição da Pessoa com Deficiência no Âmbito do Vivido}

Os fenômenos psíquicos como pensar, emocionarse e imaginar-se só se dão em ato. Isto quer dizer que é um corpo que pensa, um corpo que imagina, um corpo que se emociona. Só há uma forma de ser no mundo, ou seja, estar situado no mundo, à direita da mesa em frente a estante, por exemplo. A deficiência é ainda uma maneira de ser no mundo. "A cegueira, o daltonismo, a miopia, representam originariamente o modo como há um mundo para mim, ou seja, definem meu sentido visual enquanto facticidade de meu surgimento" (Sartre, 1943/1997, p. 404). Certamente há diferenças por demais significantes entre pessoas que adquirem uma incapacidade física e aquelas que, já, nascem com essa incapacidade.

Deve haver certa diferença entre aquelas pessoas que adquirem uma incapacidade física e aquelas que nascem com uma incapacidade física. Oliveira (2004), ao tratar da corporeidade do sujeito com uma deficiência física lembra a necessidade de pensar sobre os aspectos psíquicos da deficiência. Nós reiteramos a perspectiva de Oliveira (2000) e acrescentamos que o corpo que Eu tenho mudou e certamente haverá um corpo Para-Outro que a pessoa com uma deficiência não irá controlar, terá que lidar com a visão que o outro tem sobre ela e lhe entrega ainda mais uma dimensão de seu ser no mundo. Entretanto são múltiplas as possibilidades de experiências do corpo que Eu sou.

Oliveira (2000) justifica esta necessidade pelo número de pessoas que adquirem uma deficiência pelo Acidente Vascular Cerebral - AVC - e amputações defendendo que é preciso compreender os aspectos da deficiência de modo particular devido às diferenças considerandose cada pessoa.

Segundo Oliveira (2000, p. 437), "a incapacidade adquirida, não discutindo para já a influência da sua maior ou menor gravidade, pode desafiar muitos dos princípios fundamentais da vida de qualquer pessoa." Desse modo ocorre uma ruptura no percurso normal na vida da pessoa podendo alterar o significado de 
tempo, espaço e sua condição de realizar julgamentos. Neste contexto, a pessoa "confronta-se com uma situação nova, radicalmente diferente, capaz de lhe limitar o desempenho das suas obrigações sociais, profissionais e familiares como até então sucedia” (Oliveira, 2000, p. 437).

No caso da pessoa que adquire uma deficiência, o que muda? A pessoa com uma deficiência vive suas experiências, se relaciona com os instrumentos/utensílios e com as outras pessoas numa condição corporal diferente da condição anterior. Durante toda a sua vida constituiu um esquema corporal, isto é, um conjunto de significações encarnadas no seu próprio corpo. Serão estas mesmas significações a serem construídas a partir da sua condição corporal e possibilidades atuais de agir no mundo? Pensamos que sim. Oliveira (2000) faz considerações a respeito da pessoa na situação de incapacidade adquirida, referindo-se que:

Numa fase aguda, o indivíduo depara-se com duas opções: empreender o mais rapidamente possível para a sua recuperação total ou a morte. Usualmente, o facto de continuar a viver, ainda que de forma radicalmente diferente, constitui uma enorme tarefa de adaptação, exigindo lidar com a perca (p. 438).

Continuar a viver é ainda lançar-se para um futuro de uma forma nova, onde a própria pessoa faz a sua escolha. Entretanto, é necessário considerar o contexto antropológico em que o preconceito pode ser vivido; o apoio oferecido pela rede sociológica da pessoa com uma deficiência; e a biografia da pessoa com a deficiência. E no desvendar da biografia podemos averiguar que dificuldades estão efetivamente ligadas à deficiência e que dificuldades estão relacionadas a outras nuances de sua vida como pessoa com deficiênca.

\section{Considerações Finais}

A fenomenologia, sobretudo, a obra de Jean PaulSartre e de Maurice Merleau-Ponty merecem ser visitadas, uma vez que oferece novas possibilidades de conhecer e intervir nos âmbitos gerais da educação e da saúde e especificamente em psicologia. Porquanto, podem fundamentar ainda mais estudos que visam a compreensão da corporeidade e a intervenção frente aos mais variados fenômenos humanos.

A reflexão sobre as contribuições da fenomenologia nos parece ser, por um lado, absolutamente importantes para pensar a deficiência física e por outro, fundamentais para intervir sobre os aspectos psicológicos advindos desta deficiência. Ademais, pode servir de suporte teórico tanto para psicólogos como para médicos, fisioterapeutas e professores.
Consideramos ainda que os conceitos aqui apresentados devem ser examinados atentamente a fim de superarmos a cisão corpo/mente e a concepção do corpo mecânico, ganhando espaços de reflexão mais amplos, como por exemplo, na bioética.

\section{Referências}

Dartigues, A. (2000). O que é fenomenologia? São Paulo: Centauro Editora.

Debord, G. (2003). A Sociedade do Espetáculo (eBookLibris). Disponível em: http://www.cisc.org.br/portal/biblioteca/ socespetaculo.pdf

Le Breton, D. (2007). A Sociologia do Corpo. Petrópolis: Vozes.

Furlan, A. (1999). El lugar del cuerpo en una educación de calidad. Lecturas: Educación Física y Deportes (Online), Buenos Aires, v. 4, n. 13. Disponível em: http://www.efdeportes. com/efd13/afurlan1.htm

Gonçalves Junior, L.; Ramos, G.N.S. \& Couto, Y.A (2003). A motricidade humana na escola: da abordagem comportamental à fenomenológica. Revista CorpoConsciência (Santo André), v. 12, p. 23-37.

Merleau-Ponty, M. (2006). Fenomenologia da Percepção. São Paulo: Martins Fontes (Original publicado em 1945).

Monteiro, A.A. (2009). Corporeidade e educação física: histórias que não se contam na escola! Dissertação de Mestrado em Educação Física, Universidade São Judas Tadeu, São Paulo.

Nóbrega, T.P. (2007). Merleau-Ponty: O filósofo, o corpo e o mundo de toda a gente! XV Congresso Brasileiro de Ciências do Esporte e II Congresso Internacional de Ciências do Esporte, Recife. Disponível em: http://www.cbce.org.br/ cd/resumos/129.pdf.

Oliveira, R.A. (2000). Elementos psicoterapêuticos na reabilitação dos sujeitos com incapacidades físicas adquiridas. Análise Psicológica, 4 (18), 437-453.

Oliveira, R.A. (2004). O sujeito e o corpo perante a incapacidade Revista Portuguesa de Psicossomática, 1 (6), 63-67.

Ortega, F. (2005a). Corpo e Tecnologias de Visualização Médica: entre a Fragmentação na Cultura do Espetáculo e a Fenomenologia do Corpo Vivido. Physis: Revista de Saúde Coletiva, 15 (1), 237-257.

Ortega, F. (2005b). Fenomenologia da visceralidade. Notas sobre o impacto das tecnologias de visualização médica na corporeidade. Cadernos de Saúde Pública, 6 (21), 1875-1883.

Ortega, F. (2007). Corporeidade e biotecnologias: uma crítica fenomenológica da construção do corpo pelo construtivismo e pela tecnobiomedicina. Ciência $\&$ Saúde Coletiva, 12 (2), 381-388 
Rechineli, A.; Porto, E.T.R. \& Moreira, W.W. (2008). Corpos deficientes, eficientes e diferentes: uma visão a partir da educação física. Revista Brasileira de Educação Especial, 14 (2), 293-310.

Sartre, J-P. (1968). Materialismo y revolución. Em Situações III [pp. 89-142]. Buenos Aires: Editora Losada, S. A. (Original de 1964).

Sartre, J-P. (1987). Sartre no Brasil: a Conferência de Araraquara. Araraquara: UNESP (Original de 1960).

Sartre, J-P. (1997). O ser e o nada - Ensaio de Ontologia Fenomenológica. Petrópolis: Vozes (Original publicado em 1943).

Schneider, D.R. (2002). Novas Perspectivas para a Psicologia Clínica - um estudo a partir da obra "Saint Genet: comédien et martyr" de Jean-Paul Sartre. Tese de Doutorado em Psicologia Clínica. Pontifícia Universidade Católica de São Paulo, São Paulo.
Andréa Luiza da Silveira - Psicoterapeuta e Psicóloga do trabalho, Mestre em Engenharia de Produção pela Universidade Federal de Santa Catarina (2003), Docente da Universidade Comunitária da Região de Chapecó (Unochapecó).E-mail: deasilveira@gmail.com

Rita de Cássia Silveira Cambruzzi - Mestre em Educação Especial e Doutoranda em Educação Especial pela Universidade Federal de São Carlos (UFSCar). Psicóloga da Fundação Catarinense de Educação Especial.E-mail: ritacambruzzi@yahoo.com.br

Maria da Piedade Resende da Costa - Mestre em Educação Especial pela Universidade Federal de São Carlos (UFSCar) e Doutora em Psicologia pela Universidade de São Paulo (USP). Professora permanente do Programa de Pós-Graduação em Educação Especial da Universidade Federal de São Carlos com orientação no mestrado e doutorado e supervisão de pós-doutorado. É líder do Grupo de Pesquisa Educação Especial desde 1992. Endereço Institucional: Universidade Federal de São Carlos, Centro de Educação e Ciências Humanas, Departamento de Psicologia. Rodovia Washington Luis, Km 235 (Monjolinho). Caixa Postal 676. CEP 13.565-905. São Carlos/SP. E-mail: piedade@ufscar.br

Rose Silveira Von Hertiwig - Psicóloga Clínica e psicoterapeuta. E-mail: rosevonhertwig@globo.com

Recebido em 23.06.2011

Aceito em 22.11.2011 